\title{
HERBS AS ANTICANCER AGENTS
}

\author{
Raviraja Shetty G. \\ Agricultural \& Horticultural Research Station, Ullal, Mangalore \\ (University of Agricultural \& Horticultural Sciences, Shimoga), Karnataka
}

\begin{abstract}
Cancer is a frightful disease and represents one of the biggest health-care issues for the human race and demands a proactive strategy for cure. Plants are reservoirs for novel chemical entities and provide a promising line for research on cancer. Plants have been used for medical purposes since the beginning of human history and are the basis of modern medicine. Most chemotherapeutic drugs for cancer treatment are molecules identified and isolated from plants or their synthetic derivatives. The selected and careful use of this plant may definitely in antiangiogenic therapy and thus in cancer management. Plant derived anticancer agents are effective inhibitors of cancer cells lines, making them in high demand. Exploitation of these agents needs to be managed to keep up with demands and be sustainable. Effort has been made through this review to highlight the role of medicinal plants in cancer therapy.
\end{abstract}

Keywords: Cancer, medicinal plants, diagnosis, therapy and herbs.

\section{INTRODUCTION}

Cancer is generally considered to comprise more than 100 diseases, each characterized by uncontrolled growth and spread of abnormal cells. It is resulting from a chain of multiple genetic changes causing a lots of typical growth controls, leading to unregulated growth, lack of differentiation, apoptosis, genomic instability and metastasis. There are several internal (inherited mutation, hormones, immune condition and mutation that occur from metabolism) and external (tobacco, chemicals, radiation and infectious organisms) factors that cause cancer (Anon., 2012).

There are mainly four types of cancer according to body tissue from which they develop

1. Carcinoma : arises from epithelial cells lining lung, liver, breast, prostate, pancreas, etc

2. Sarcoma: develops from the cell of muscles, nerves and bones
3. Lymphoma: arises from cells in lymph glands

4. Leukemia: it is the cancer developing from blood forming tissue

\section{IMPORTANCE OF HERBS}

\section{IN ANTI-CANCER THERAPY}

The world health organization (WHO) has listed 21,000 plants, which are used for medicinal purpose around the world. Among these 2,500 species are in India, out of which 150 species are used commercially on a fairly large scale. India is the largest producer of medicinal herbs and is called as "botanical garden of the world". Natural Products, especially plants, have been used for the treatment of various diseases for thousands of years. Terrestrial plants have been used as medicines in Egypt, China, India and Greece from ancient time and an impressive number of modern drugs have been developed from them. The first written records on the medicinal uses of plants appeared in about 2600 BC from the Sumerians and Akkaidians. 
The "Ebers Papyrus", the best known Egyptian pharmaceutical record, which documented over 700 drugs, represents the history of Egyptian medicine dated from 1500 BC. The Chinese Materia Medica, which describes more than 600 medicinal plants, has been well documented with the first record dating from about 1100 BC. Documentation of the Ayurvedic system recorded in Susruta and Charaka dates from about 1000 BC.

Plants have a long history of use in the treatment of cancer. Hartwell, in his review of plants used against cancer, lists more than 3000 plant species that have reportedly been used in the treatment of cancer. The search for anti-cancer agents from plant sources started in earnest in the 1950s with the discovery and development of the vinca alkaloids, vinblastine and vincristine, and the isolation of the cytotoxic podophyllotoxins. These discoveries prompted the United States National Cancer Institute (NCI) to initiate an extensive plant collection program in 1960. This led to the discovery of many novel chemotypes showing a range of cytotoxic activities, including the taxanes and camptothecins (Kaur et al., 2011).

Search for new medicine is a continuous endeavour to combat cancer. Many plants, around us, have been reported to possess anti-cancerous property (Nirmala et al., 2011). There is an acute need to fight cancer with herbs. Tropical regions of world have a high amount of diversity in medicinal plants and these plants provide chemical foundation to pharmaceutical research in cancer therapy. In this seminar, the clinical research works on anticancer property of some tropical medicinal plants is covered.

\section{CANCER GLOBALLY}

Every year, cancer is diagnosed in 10 million people and accounts for 7.1 million (12.5\% of global total) deaths. It is second to cardiovascular diseases as a cause of death. Global cancer rates could increase by $50 \%$ to 15 million by 2020 (WHO). This alarming increase is due to smoking and adoption of unhealthy lifestyles. In United States, every one out of four people die because of cancer.

\section{DIAGNOSIS OF CANCER}

There are mainly three ways (therapies) to cure or to treat cancer. 'Surgery' is the oldest known treatment among the cancer treatments. In this, the growing cancer cells or tumors are removed by surgery. Cancer can be cured by this method only if it has not metastasized. Cancer can be cured by radiation which is known as 'radio therapy'. In this therapy cancer cells are treated and killed with high energy rays (X, gamma, and UV rays). The rays not only kill cancer cells but also affect the surrounding normal cells and may cause side effects. 'Chemotherapy' is the safer, effective treatment for cancer. In this method, toxic drugs are used with main focus to trigger the apoptotic programme. These drugs act on cancer cells by inhibition, blocking effect, anti progression, etc. The drugs may be from natural sources or synthetic sources or both. Natural sources include plants, microbes, minerals, etc. with plants as major source.

Table 1: Some anti-cancerous plants used in cancer therapy.

\begin{tabular}{|l|l|l|}
\hline Plant species & Experiments on various cancer cells & Mechanism of action \\
\hline Catharanthus roseus & Leukemias, lyphomas and lung cancer & Mitotic block \\
\hline Berberineeris sp. & Breast, prostrate and lung cancer & Apoptosis \\
\hline Gloriosa superba & Leukemia & Anti-mitotic \\
\hline Curcuma longa & Colon and pancreatic cancer & Unknown \\
\hline Zingiber officinalis & Breast and lung cancer & Un known \\
\hline Andrographis paniculata & Colon cancer & Apoptosis \\
\hline Palargonium graveolens & Breast cancer & Un known \\
\hline Boesenbergia pandurata & Breast and colon cancer & Apoptosis and cell cycle arrest \\
\hline Ruta graveolens & Colon \& prostate cancer & Cell cycle arrest \\
\hline Ocimum sanctum & Lung cancer & Inhibition of invasion \\
\hline Magnolia officinalis & Prostate cancer & Not known \\
\hline Achyranthes aspera & Pancreatic cancer & Apoptosis \\
\hline Solanum nigrum & colon and breast cancer & Apoptosis \\
\hline Artemisia vulgaris & Prostate \& colon cancer & Apoptosis \\
\hline
\end{tabular}




\section{Solanum nigrum and Artemisia vulgaris}

Solanum nigrum is commonly called as black nightshade and belongs to family solanaceae. Berries are the economic parts in this. It is mainly known for its antipyretic and diuretic properties and has a long history of use in the treatment of inflammation, edema, mastitis, cirrhosis of liver in oriental medicine (Nawab et al., 2011). Artemisia vulgaris is a member of asteraceae family. Artemisin is the active principle in this. In traditional medicines, it is used against intestinal worms, nervous and spasmodic affections, asthma, sterility, functional bleeding of the uterus and menstrual complaints (Tan et al., 1998).

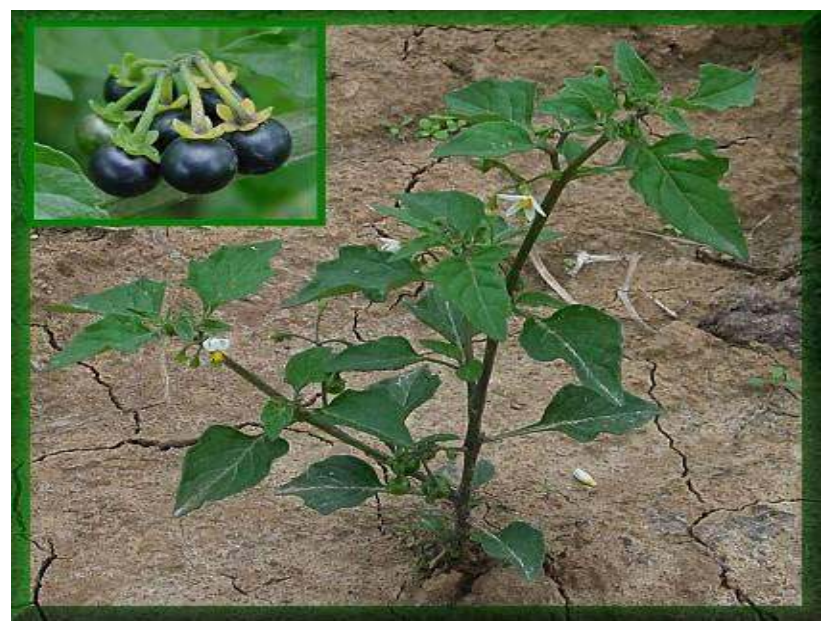

Components of the plants viz. Artemisia vulgaris, Cichorium intybus, Smilax glabra, Solanum nigrum and Swertia chirayta have been used in traditional folk medicine to treat various human ailments; however, the anticancer properties have not been elucidated. Nawab et al. (2011) evaluated the anticancer properties of aqueous extracts of these plants against various human prostate, breast and colorectal cancer cells. The Aqueous extracts of plant parts like inflorescence (Artemisia vulgaris), seeds (Cichorium intybus), rhizome (Smilax glabra), berries (Solanum nigrum) and whole plant (Swertia chirayata) were considered for assessment of anticancer properties.

\section{Boesenbergia pandurata}

Members of the Zingiberaceae family have been reported to possess both antioxidant and anti-inflammatory activity. Such antioxidant and anti-inflammatory compounds have often been shown to be effective as anticancer agents (Surh, 1999). Boesenbergia pandurata or Kaempferia pandurata, commonly called as chinese ginger or finger root, is a member of zingiberaceae family. The chemical constituent (active principle) present in this is panduratin. The fresh rhizomes are used in cooking and traditional medicine to treat diarrhoea, dermatitis, dry cough, and mouth ulcers (Hyene, 1987).
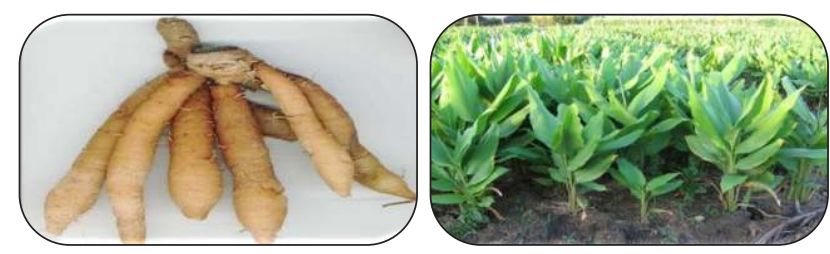

\section{Rutagraveolens}

Ruta graveolens is a medicinal and culinary plant that is native to the Mediterranean region of southern Europe and northern Africa. Widely grown in different parts of the world, this herb has historically been in use since the ancient times. Its documented therapeutic uses include the treatment of inflammatory conditions, eczema, ulcers, arthritis, fibromyalgia, antidote for venoms, insect repellent, and as an abortifacient (Fadlalla et al., 2011). They examined the potency of an extract from $R$.graveolens on cancer cell lines. The study shows that this extract has potent anticancer activity, exhibited through strong anti-proliferative and anti-survival effects on cancer cells.
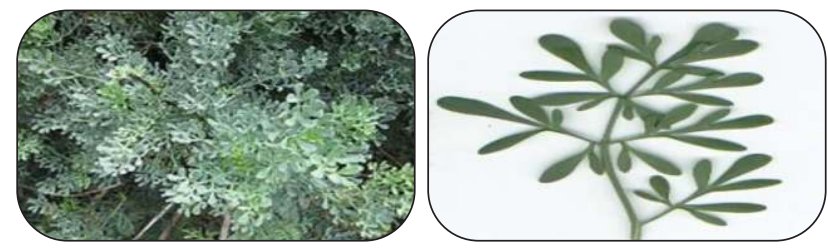

\section{Achyranthes aspera}

The leaves and roots of Achyranthes aspera (Family Amaranthacea) is used as a therapeutic agent for cancer in Ayurvedic medical system. However, its anti tumor properties have not been validated by current scientific approaches, thus remain anecdotal. Methanol extract of A. aspera leaves (LE) have cellular specific, dose and time dependent cytotoxicity to human cancer cells in vitro with reduced toxicity to normal cells. Some genes involved in tumor metastasis and angiogenesis were regulated by LE. However the in vivo efficacy of LE is not known (Subbarayan et al., 2010).
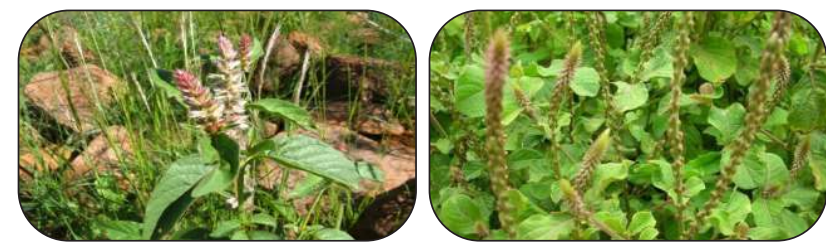

\section{Curcuma longa}

Docetaxel (Doc) has demonstrated extraordinary anticancer effects in vitro and in vivo against a variety of tumors, including lung, ovaries, breast cancers, etc. As recommended by the National Comprehensive Cancer Network, Doc is considered as first-line chemotherapy for the treatment of non-small cell lung cancer (Annon., 2011). 
However, chemotherapeutics sometimes lead to severe toxicity at their therapeutic dose even though the response rate of single drug chemotherapy remains 20\% (Baker et al., 2008). In order to achieve higher antitumor efficacy and minimize the emergence of resistance, to search novel chemotherapy sensitizers become the focus in the field of cancer therapy. Curcumin (Cum), the principal polyphenolic curcuminoid, obtained from the turmeric (Curcuma longa) rhizome, has been reported for its potential chemopreventive and chemotherapeutic activity in a series of cancers. For example, in vitro and in vivo experiments showed Cum could inhibit skin squamous cell carcinoma growth and block tumor progression (Phillips et al., 2011).

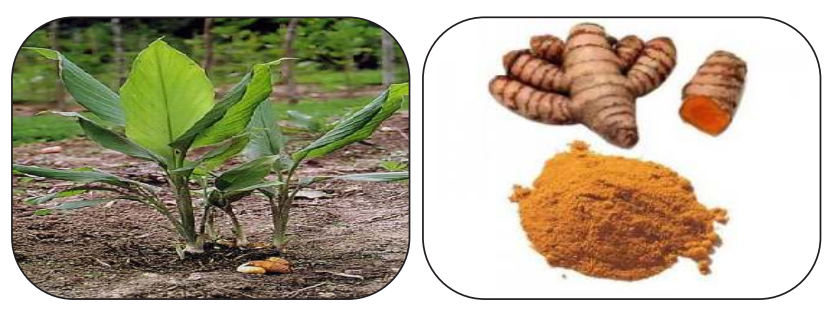

\section{Ocimum sanctum}

Ocimum sanctum Linne (OS), commonly known as 'Holy basil' has attracted in the Ayurvedic system of medicine (Singh et al., 1996). It has been known that anti-oxidant enzymes play crucial roles in metastatic tumor growth (Llovet and Bruix, 2008). Kim et al. (2010) investigated the potential of ethanol extract of OS (EEOS) as a potent antimetastatic candidate for lung cancer in vivo and in vitro.

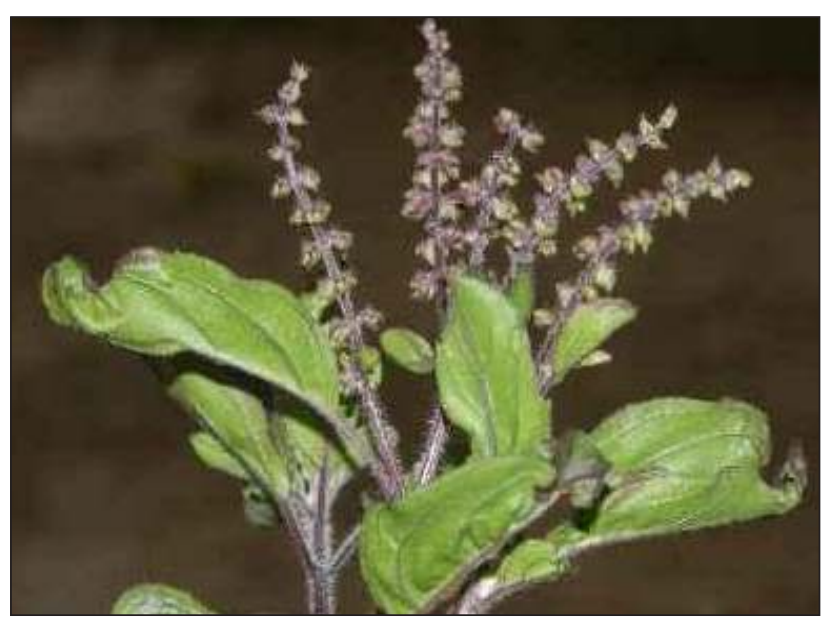

Withania somnifera

The alcoholic extract of the roots of the Indian medicinal plant, Withania somnifera Dunal was found to inhibit the growth of Sarcoma 180 and Ehrlich ascites carcinoma in mice. The major component in the extract responsible for the antitumor effect was found to be the withanolide, withaferin A(WA), a steroidal lactone.
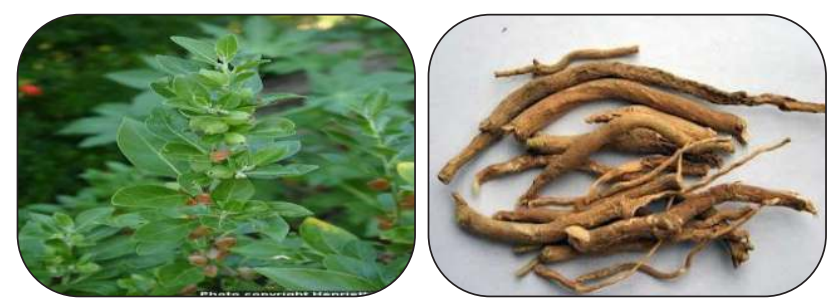

\section{Magnolia officinalis}

Magnolol, a hydroxylated biphenyl compound isolated from the stem bark of the Chinese herb Magnolia officinalis (Magnoliaceae), is commonly used to treat acute pain, cough, anxiety, and gastrointestinal disorders in Easter Asia. Magnolol also has been reported to exhibit anticancer activity, including induction of apoptosis in cultured HepG2 human hepatoma and Colo205 colon cancer cells.

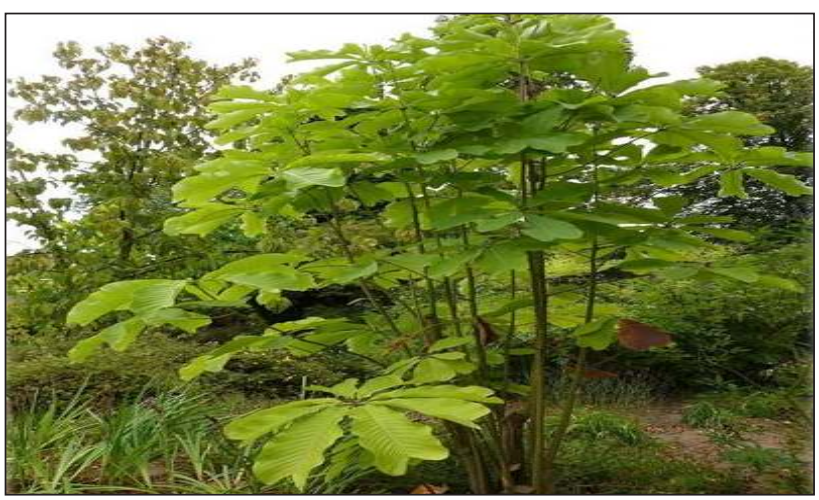

\section{CONCLUSION}

To conclude, Medicinal plants maintain the health and vitality of individual and also cure various diseases including cancer without causing toxicity. Natural products discovered from medicinal plants have played an important role in treatment of cancer. Plants possess good immunomodulatry and antioxidant properties leading to anticancer activity. The tropical world is an important, major source of medicinal plants.

Anticancer compounds from many plants have been found significantly active against various cancer cells in animal models. Further research on precise molecular mechanisms and targets for cell growth inhibition may lead to better treatment of cancer and it will be helpful to exploit novel anticancer drugs from medicinal plants.

\section{REFERENCES}

1. A n o n y mous, 2012 , h t t p : / / w w w . medicalnewstoday. com/info/ canceroncology/\#.UJo6gbFlII8.

2. Fadlalla, K., Watson, A., Yehualaeshet, T., Turner, T. and Samuel, T., 2011, Ruta graveolens extract 
induces DNA damage pathways and blocks Akt activation to inhibit cancer cell proliferation and survival. Anticancer res., 31: 233-242.

3. Hyene, K., 1987, Zingiberaceae. In: Tumbuhan Berguna Indonesia Book 1 (in Indonesian). Badan Litban Kehutanan, Jakarta, : 567-605.

4. Kaur, R., Kapoor, K. and Kaur, H., 2011, Plants as a source of anticancer agents. J. Nat. Prod. Plant Resour., 1 (1): 119-124.

5. Kim, S. C., Magesh, V., Jeong, S. J., Lee, H. J., Ahn, K. S., Lee, H. J., Lee, E. O., Kim, S. H., Lee, M. H., Kim, J. H. and Kim, S. H, 2010, Ethanol extract of Ocimum sanctum exerts anti-metastatic activity through inactivation of matrix metalloproteinase-9 and enhancement of anti-oxidant enzymes. Food Chem. Toxicol., 48: 1478-1482.

6. Llovet, J. M., Bruix, J., 2008, Molecular targeted therapies in hepatocellular carcinoma. Hepatology, $\mathbf{4 8}$ (4), :1312-1327.

7. Nawab, A., Yunus, M., Mahdi, A. A. and Gupta, S., 2011, Evaluation of anticancer properties of medicinal plants from the Indian sub-continent. Mol. Cell Pharmacol., 3 (1): 21-29.
8. Nirmala, M. J., Samundeswari, A. and Sankar, D. P., 2011, Natural plant resources in anti-cancer therapy- Areview. Res. Plant Biol., 1 (3): 01-14.

9. Phillips, J. M., Clark, C., Ferdinandez, H. L., Medlin, M. T., Rong, X., Gill, J. R. and Clifford, J. L., 2011, Curcumin inhibits skin squamous cell carcinoma tumor growth in vivo. Otolaryngol Head Neck Surg. 145: 58-63.

10. Subbarayan, P. R., Sarkar, M., Impellizzeri, S., Raymo, F., Lokeshwar, B. L., Kumar, P., Agarwal, R. P., Ardalan, B., 2010, Anti-proliferative and anticancer properties of Achyranthes aspera: specific inhibitory activity against pancreatic cancer cells. $J$. Ethnopharmacol., 131, 78-82.

11. Surh, Y. J., 1999, Molecular mechanisms of chemopreventive effect of selected dietary and medicinal phenolic substances. Mutat. Res., 428: 305 327.

12. Tan, R. X., Zheng, W.F., Tang, H.Q., 1998, Biologically active substances from the genus Artemisia. Planta Med.64:295-302. 